\title{
O PRINCÍPIO DA SEGURANÇA JURÍDICA EM MATÉRIA TRIBUTÁRIA
}

\author{
Paulo de Barros Carvalho \\ Professor Titular do Departamento de Direito \\ Econômico-Financeiro da Faculdade de Direito da \\ Universidade de São Paulo e da Pontifícia \\ Universidade Católica de São Paulo
}

\begin{abstract}
Resumo:
Sendo objeto do mundo da cultura, o Direito e, mais particularmente, as normas jurídicas estão sempre impregnadas de valor. Esse componente axiológico, invariavelmente presente na comunicação normativa, experimenta variaçōes de intensidade de norma para norma, de tal sorte que existem preceitos fortemente carregados de valor e que, em função do seu papel sintático no conjunto, acabam exercendo significativa influência sobre grandes porçōes do ordenamento, informando o vector de compreensão de múltiplos segmentos. Em Direito, utilizase o termo "princípio" para denotar as regras de que falamos, sendo esse o objeto do presente trabalho. Nele, a amplitude semântica do vocábulo "princípio" foi cuidadosamente examinada, bem como sua classificação e função dentro do conjunto normativo. Foram objeto de análise, também, alguns princípios constitucionais tributários encontrados no sistema positivo brasileiro, dando-se especial atenção ao sobreprincípio da segurança jurídica e respectivas implicações na esfera do Direito Tributário.
\end{abstract}

\begin{abstract}
:
Being an object of the cultural world, the law, and more in particular, the legal rules are always impregnated by value. This axiological component, invariably present in the standard communication, undergoes variations in intensity from norm to norm, in such a way that there are precepts that are heavily loaded with value and that, in function of their syntactic role in the total, end up exercising significant influence on large parts of the legislation, providing information to the vector for comprehension of multiple segments. In Law the term "principle" is used to describe the rules that we speak about and this is the object of the present work. In this work, the semantic extensions of the word "principle" were carefully investigated, as well as their classification and function in the standard set of norms. Also object of analysis were some constitutional fiscal principles that can be found in the positive Brazilian system and special attention was given to the principle of legal security and the respective implications in the field of Fiscal Law.
\end{abstract}

Unitermos: Direito Tributário; princípio; sobreprincípio; segurança jurídica. 
1. Amplitude semântica do vocábulo "princípio"

No campo das significações, o uso do signo "princípio" oferece farta variedade conotativa, de tal sorte que alcança todas as circunscrições de objetos, atuando nas quatro regiões ônticas. É uma palavra que freqüenta com intensidade o discurso filosófico, expressando o "início", o "ponto de origem”, o "ponto de partida”, a "hipóteselimite" escolhida como proposta de trabalho. Exprime também as formas de síntese com que se movimentam as meditações filosóficas ("ser", "não-ser", "vir-a-ser" e "deverser"), além do que tem presença obrigatória ali onde qualquer teoria nutrir pretensões científicas, pois toda a ciência repousa em um ou mais axiomas (postulados). Cada "princípio" seja ele um simples termo ou um enunciado mais complexo, é sempre passível de expressão em forma proposicional, descritiva ou prescritiva. Agora, o símbolo lingüístico que mais se aproxima desse vocábulo, na ordem das significações, é "lei" Dizemos, por isso, que há uma lei, em Física, segundo a qual "o calor dilata os corpos" "os metais são bons condutores de eletricidade" "a matéria atrai a matéria na razão direta das massas e na razão inversa do quadrado das distâncias"; na Metafísica, apanhando como exemplo a filosofia de Schopenhauer, que a "vontade se constitui naquele ímpeto cego e irresistível que consubstancia o querer-viver universal": entre os

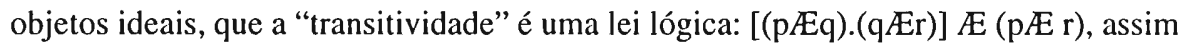
como a "reflexividade" também o é (xRy) $Æ(y R x)$; em Economia, falamos em "lei da oferta e da procura" ao mesmo tempo em que afirmamos que a "História fundamentalmente diacrônica" para ingressarmos nos domínios dos objetos culturais, onde ao lado de "leis" ou "princípios" descritivos, vamos encontrar as prescrições éticas, religiosas, morais etc., que ostentam o porte de autênticos "princípios" Como desdobramento dessa descritividade e prescritividade, lidamos com "princípios gerais" e "específicos" "explícitos" ou "implícitos" classificando-os como "empíricos" "lógicos", "ontológicos", "epistemológicos" e "axiológicos" Tudo isso é índice da riqueza significativa que a palavra exibe, compelindo-nos a um esforço de elucidação para demarcar o sentido próprio que desejamos imprimir ao vocábulo, dentro de seu plano de irradiação semântica. Impõe-se uma decisão para cada caso concreto, principalmente se a proposta discursiva pretender foros de seriedade científica.

2. O Direito no mundo dos objetos culturais.

Enquanto camada de linguagem prescritiva de condutas, o Direito Positivo é uma construção do ser humano. Nesse sentido, dista de ser um dado 
simplesmente ideal, não lhe sendo aplicáveis, também, as técnicas de investigação do mundo natural. As unidades normativas selecionam fatos e regulam comportamentos, fatos e condutas recolhidos no campo social. Ora, o fato social, como processo de relação, é um fenômeno com sentido e, sem ele (sentido), que imprime direção aos fatos sociais, é impossível compreendê-los. Os fatos jurídicos, quer os previstos nos antecedentes das normas, quer os prescritos na fórmula relacional dos conseqüentes, apresentam-se na forma de fenômenos físicos (relações de causa e efeito) mais o sentido, isto é o fim jurídico que os permeia. Sem a significação jurídica que presidiu a escolha do evento e inspirou a regulação da conduta, não há falar-se em fatos jurídicos e relações jurídicas. Essa parte do mundo empírico reivindica tratamento especial, que atente para seu lado dinâmico de ações e reações, no esquema de causa e efeito, mas que também o considere, fundamentalmente, naquilo que ele tem de significação, de sentido.

Quem se proponha conhecer o Direito Positivo não pode aproximar-se dele na condição de sujeito puro, despojado de atitudes axiológicas, como se estivesse perante um fenômeno da natureza ou uma equação algébrica. A neutralidade axiológica impediria, desde o início, a compreensão do sentido das normas, tolhendo a investigação. Além do mais, o conhecimento jurídico já encontra no seu objeto uma auto-explicação, pois o direito fala de si mesmo e este falar-de-si é componente material do objéto. Daí a função reconstrutiva do saber jurídico, expressa nas proposições descritivas da Ciência do Direito.

Demoremo-nos, porém, num ponto: se é impossível conhecer as normas do Direito Positivo sem estimar-lhes o valor, integrante que inere a todo o bem cultural, outra coisa bem distinta é compor o discurso jurídico-descritivo da Ciência aplicandothe, pela segunda vez, uma inclinação ideológica, vale dizer, estabelecendo juízos de valor que incidam nas proposições teoréticas do conhecimento científico, opinando sobre a justiça, a racionalidade ou sobre critérios de segurança ou de funcionalidade que certa ordem jurídica oferece ou não oferece, enquanto sistema de direito positivo. O jurista dogmático não deve julgar as normas do ordenamento, unicamente compreendêlas para bem descrevê-las. Assevera por isso Lourival Vilanova que "o sujeito do conhecimento, quando trava contacto com o mundo dos conteúdos sociais e históricos, vem a travar contacto consigo mesmo e ao invés da relação pura sujeito-objeto, mesclase essa relação com uma inevitável parcela de atitude prático-valorativa" 1

Acontece que o "dever-ser" na modalidade do jurídico, pressupõe o "poder-ser" isto é, a possibilidade objetiva do comportamento regulado vir a realizar-se na plataforma das interações humanas. E esse "poder-ser" da conduta nada mais é que a

1. O problema do objeto da Teoria Geral do Estado, Recife, 1953. 
liberdade de cumprir a ação prevista ou de omiti-la. Eis aqui o valor, expressão de um dos mais caros e proclamados bens da história do homem, fincado, irremediavelmente, na própria raiz do direito e sem o qual a formulação normativa carecerá de sentido deôntico. Inexista a liberdade de exercer a conduta ou de atuar sua omissão e a disciplina da regra jurídica trará consigo um "sem-sentido" prescritivo, não de ordem sintática, mas de caráter semântico. Tal valor é um "prius" da análise jurídico-normativa.

3. Os "princípios", na textura das várias linguagens jurídicas.

Empregamos "linguagem jurídica" para referir os sistemas de comunicação que se prestam a realizar ou a mencionar o fenômeno jurídico. Por essa locução designaremos o chamado "Direito Positivo", a Dogmática Jurídica ou Ciência do Direito em sentido estrito, bem como todos aqueles setores do conhecimento que toam o sistema do Direito Positivo como objeto de suas indagações, ainda que não o façam em termos exclusivos. Nessa linha de pensamento, é linguagem jurídica a da Filosofia do Direito e, dentro dela, a da Lógica Jurídica, a da Epistemologia do Direito, a da Axiologia do Direito e a da Ontologia Jurídica. Mas serão também "linguagem jurídica" a Sociologia do Direito, a Antropologia Cultural do Direito, a História do Direito e tantas mais que levem em conta de objeto o sistema das normas positivadas.

De um lado, como linguagem-objeto, temos determinada ordem jurídiconormativa, operando num ponto do tempo histórico e sobre dado espaço territorial; de outro, como metalinguagem descritiva, a Ciência do Direito em sentido estrito ou Dogmática Jurídica, voltada somente a compreender e relatar sua linguagem-objeto. A Filosofia do Direito comparece aqui na condição de metalinguagem se suas reflexões incidirem sobre a linguagem do Direito Positivo. As meditações filosóficas, entretanto, trabalham muitas vezes sobre construções científicas, momento em que assumem a hierarquia de uma metalinguagem. Outro tanto vale para os demais segmentos contidos no âmbito das "ciências jurídicas em sentido amplo"

Firmados nessas ponderações, é lícito assertar a existência de "princípios jurídicos" em todos os setores da investigação do Direito. E é com tal dimensão significativa que enunciamos os princípios ou leis ditas ontológicas: "tudo que não estiver juridicamente proibido, estará juridicamente permitido" e "tudo que não estiver juridicamente permitido, estará juridicamente proibido"; os princípios jurídicos empiricamente verificáveis, como, por exemplo: "de acordo com a Constituição vigente, o Brasil é uma república federativa" (princípios federativo e republicano). Há o princípio 
lógico jurídico segundo o qual "toda conduta obrigatória está necessariamente permitida" (e linguagem formalizada, diremos: (OpÆPp), em que "O" é o modal "obrigatório", "P" o "permitido" e "p" uma conduta qualquer). Esse "princípio" ou "lei" da Lógica Deôntico-Jurídica, aliás, é o fundamento da conhecida "ação de consignação em pagamento". Ao lado dele, por oportuno, podemos indicar a lei lógica da "idempotência do conjuntor", aplicada ao Direito: "Se duas ou mais normas serviremse do mesmo antecedente e prescreverem a mesma regulação da conduta, então todas elas eqüivalem a uma só". Expliquemos o princípio, formalizando-o e, depois, mediante um exemplo prático e objetivo. A "lei" da idempotência do conjuntor (utilizada para o universo jurídico) assim se exprime, em linguagem formal: (Vp.Vp.Vp.Vp.Vp)=Vp, onde "V" é a notação simbólica da "proibição"; "p" uma conduta qualquer; " ", o conectivo da conjunção lógica; e "=", a equivalência. No sistema da Constituição, de 1967, havia três preceitos consagrando a "legalidade tributária": um genérico e dois específicos. Quer significar, por outro giro, que o legislador constitucional prescrevia: "só é permitido exigir tributo novo ou aumentar os existentes por meio de lei" Tal era o conteúdo de três normas constitucionais. Pelo princípio da idempotência do conjuntor, os três eqüivaliam a apenas um.

Bem, até aqui vimos princípios empíricos, ontológicos e lógicos. Examinemos outros. A "norma fundamental” kelseniana é um princípio epistemológicojurídico, colocado na condição de pressuposto da atividade cognoscitiva do Direito. Sem a "norma fundamental" ou regressaríamos ao infinito, jamais começando a tarefa cognoscente, ou sacrificaríamos o cânone do isolamento do objeto, sem o que o estudo não atingiria a dignidade de ciência. Outros princípios epistemológico-jurídicos são os da "homogeneidade sintática" e da "heterogeneidade semântica" das unidades normativas. Já nos domínios axiológicos mencionemos o "princípio da Justiça" da "igualdade", da "segurança", da "racionalidade" entre muitos outros.

Vistos por outro prisma, os "princípios" seriam gerais (a legalidade referida no art. $5^{\circ}$ II, da Constituição de 1988) ou específicos (a legalidade tributária instituída no art. 150, I, do mesmo Estatuto). Além disso, há os explícitos (art. 150, III - princípio da anterioridade tributária) e os implícitos (princípio da isonomia das pessoas políticas - União, Estados, Distrito Federal e Municípios). Cumpre observar que os princípios mencionados estão distribuídos entre a linguagem-objeto (direito positivo) e as metalinguagens jurídicas acima indicadas. Pois bem. Demos exemplos, tecemos considerações, elucidamos algum conteúdo, mas permaneceu aberta a questão principal: que é princípio? 
4. Os “princípios" e a compreensão do Direito.

Tomaremos como hipótese de trabalho o estudo do Direito, sob o ponto de vista dogmático, a partir das estruturas normativas existentes aqui e agora, que se projetam sobre a realidade social para ordená-la, no que tange às relações interpessoais que nela se estabelecem, canalizando o fluxo das condutas em direção a certos valores que a sociedade anela e quer implantados. Reconhecemos no fenômeno jurídico algo extremamente complexo, em que interferem fatores de naturezas distintas, num intensivo processo de miscigenação. Afigura-se-nos um trabalho dificílimo ingressar em sua ontologia, para extrair dados de sua intimidade existencial, caso isto, porventura, seja possível, premissa que não pretendemos discutir. Nossa concepção há de caminhar predominantemente no padrão analítico da linguagem, respeitando aquela complexidade que salientamos como ínsita ao dado jurídico, mas ao mesmo tempo refletindo na consideração de que ali onde houver regulação jurídica haverá, inexoravelmente, proposições normativas que, escritas ou não escritas, hão de manifestar-se em linguagem. Ora, se isolarmos o universo normativo, naquilo que ele tem de fenômeno lingüístico, aparecerá diante de nós um objeto uniforme (somente normas jurídicas), todas compostas na mesma organização sintática, vale dizer, mediante um juízo hipotético em que o legislador (sentido amplo) imputa, ao acontecimento de um fato previsto no antecedente, uma relação deôntica entre dois ou mais sujeitos, como conseqüente. A previsão fáctica ou "descritor" como suposto, implica a disciplina da conduta intersubjetiva, contida no "prescritor" (Lourival Vilanova). Nunca será demasiado insistir que tanto a ocorrência factual, como o comportamento regulado, têm de ser possíveis, para que a regra venha a ser aplicada, tornando-se individualmente eficaz.

Sobressai à evidência a homogeneidade sintática suso referida, porquanto todas as unidades do sistema terão idêntica estrutura lógica, a despeito da multiplicidade extensiva de seus vectores semânticos. O Direito Positivo, então, apresentar-se-á aos olhos da Dogmática como um conjunto finito, mas indeterminado, de normas jurídicas, nas quais surpreenderemos fatos jurídicos e relações jurídicas, associados por um ato de vontade de quem pôs as regras no sistema, ato psicológico este que o cientista coloca entre parênteses metódico, para não imitir-se em territórios alheios, como, por exemplo, a Psicologia e outras ciências que poderiam explicar aspectos parciais do fenômeno. Todavia, se os fatos são jurídicos porque previstos em antecedentes normativos, remanesceria apenas um, o mais importante porque fundador do próprio sistema, sem a qualificação de jurídico, circunstância que viria a comprometer a uniformidade objetal: 
trata-se do acontecimento que dá origem à Constituição. É precisamente neste tópico que Kelsen trouxe a singela, porém genial contribuição da "norma fundamental" não posta, mas pressuposta, juridicizando aquele fato que ficara de fora, por imprimir-lhe o timbre de normatividade que lhe faltava. Fecha-se assim o conjunto, isolado na especificidade de seu objeto, uniforme porque composto tão-somente de normas jurídicas, de tal modo que nele, conjunto, não encontraremos senão descritores e prescritores, bem como suas contrapartes factuais: fatos jurídicos e relações jurídicas.

O corolário natural de tudo quanto se expôs é que o Direito Positivo, formado unicamente por normas jurídicas, não comportaria a presença de outras entidades, como, por exemplo, princípios. Estes não existem ao lado de normas, coparticipando da integridade do ordenamento. Não estão ao lado das unidades normativas, justapondo-se ou contrapondo-se a elas. Acaso estivessem, seriam formações lingüísticas portadoras de uma estrutura sintática. E qual é esta configuração lógica? Ninguém, certamente, saberá responder a tal pergunta, porque "princípios" são "normas jurídicas" carregadas de forte conotação axiológica. É o nome que se dá a regras do direito positivo que introduzem valores relevantes para o sistema, influindo vigorosamente sobre a orientação de setores da ordem jurídica.

A tipificação dos fatos que ingressam pela porta aberta das hipóteses normativas se dá mediante conceitos que o legislador formula: conceitos sobre os acontecimentos do mundo e conceitos sobre a condutas inter-humanas. Ocorre que todo o conceito, que tem como correlato expressional o termo, assim como o juízo o tem na proposição, todo o conceito, repetimos, é seletor de propriedades não-só no Direito, como em qualquer região do conhecimento. Conceituar importa selecionar caracteres, escolher traços, separar aspectos, desprezando os demais. As singularidades irrelevantes, o legislador as deixa de lado, mesmo porque são em tal quantidade que o trabalho ganharia proporções infinitas. E surge o conceito, após a aplicação do critério seletivo que o legislador adotou, critério este que nada mais é que um juízo de valor expedido em consonância com sua ideologia, tomada a palavra, neste ensejo, como pauta de valores, tábua de referências axiológicas. Assim, valora o legislador fatos e condutas, tecendo o conteúdo de significação das normas jurídicas ou, em outras palavras, saturando as variáveis lógicas daquela estrutura sintática que é comum a todas as unidades do sistema. E, ao enfatizar esse ângulo da construção jurídiconormativa, estamos apenas reconhecendo ao Direito Positivo a condição de objeto cultural, anteriormente consignada. Mantenhamos na retentiva que os objetos do mundo cultural são, invariavelmente, portadores, de valores, como também os metafísicos, o 
que não se verifica com os objetos da natureza e com os da região ôntica dos ideais, ambos axiologicamente neutros.

Até esta parte, firmamos duas proposições que aceitamos por verdadeiras: a) o Direito Positivo é formado, única e exclusivamente, por normas jurídicas (para efeitos dogmáticos), apresentando todas o mesmo esquema sintático (implicação), ainda que saturadas com enunciados semânticos diversos (heterogeneidade semântica); e b) por outro lado, como construção do ser humano, sempre imerso em sua circunstância (Gasset), é um produto cultural e, desse modo, portador de valores, significa dizer, carrega consigo uma porção axiológica que há de ser compreendida pelo sujeito cognoscente - o sentido normativo, indicativo dos fïns (thelos) que com ela se pretende alcançar.

Tal é a conclusão a que chegou Genaro Carrió, percorrendo caminhos um pouco distintos, em seu opúsculo sobre Principios Jurídicos Y Positivismo Jurídico ${ }^{2}$ : "De lo expuesto se sigue que no existe la pretendida 'diferencia lógica' entre las regras jurídicas y las pautas del tipo de la que expressa que a nadie debe permitírsele beneficiarse con su propria transgresión"

O autor argentino não chega a esse resultado partindo das premissas que adotamos. Seu objetivo foi, antes de mais nada, questionar a procedência de crítica ao positivismo jurídico, que o professor Ronald M. Dworkin, da Universidade de Oxford, apresentou com o trabalho The model of rules ${ }^{3}$, e segundo o qual a análise e consideração adequada dos princípios ficaria prejudicada pela concepção positivista do fenômeno jurídico, já que tal concepção do Direito não deixa ver o papel central que na prática os princípios desempenham. É nesse sentido que parte do sistema de Hart ${ }^{4}$ para dele extrair argumentos que demonstrem a plena compatibilidade entre as normas jurídicas, examinadas pelo ângulo de sua positivação e os princípios que com elas combinam para formar o sistema do direito positivo.

Tendo seu pensamento mais próximo de Hart, em virtude das ligações que sempre manteve com a Universidade de Oxford, Carrió entende que o positivismo de Kelsen ofereceria menos recursos à sustentação de sua tese, não lhe permitindo dar os passos de que necessitava para alojar os princípios dentro da ordem jurídica, consoante os critérios que lhe pareciam justos. Nossa posição, contudo, é bem diversa, ainda que tenhamos de intuir certos desdobramentos que o mestre de Viena não empreendeu.

\footnotetext{
2. Abeledo-Perrot, Buenos Aires, 1970.

3. University of Chicago Law Review n. 14, 1967.

4. El concepto del derecho, Buenos Aires, 1963.
} 
Que não seja isso motivo de censuras, porquanto Carlos Cossio proclamou ter ido além de Kelsen sem haver transbordado os limites do próprio sistema kelseniano (foi além de Kelsen sem sair de Kelsen). E, de fato, há desdobramentos que se afiguram como corolários de uma teoria, não extraídos por aquele que a concebeu, mas que podem perfeitamente ser sacados por quem se dispuser a segui-la.

O que importa é que Genaro Carrió chega aos mesmos resultados, nãosó admitindo a existência de "princípios" dentro da ordem jurídica positiva, como reconhecendo que não há qualquer desencontro entre o esquema lógico das normas e o daqueles primados. Ainda que não ingresse na análise dos "valores", fala, insistentemente, no "peso" dos princípios, o que basta para identificar a referida concordância.

5. "Princípios" como normas jurídicas que introduzem valores de grande importância para o ordenamento.

Recortemos determinado ambiente social. Os indivíduos da comunidade tendem a ter um núcleo consciente de valores básicos, advindos da contingência de viverem no mesmo território e no mesmo tempo histórico. Em derredor desse núcleo, contudo, a trajetória existencial de cada um vai depositando outros valores, recolhidos individualmente de tal arte que os padrões axiológicos das pessoas acabam apresentando variações muitas vezes sensíveis, repercutindo em fontes inesgotáveis de divergências, sempre que o homem se manifesta acerca de objetos de índole metafísica ou cultural. Seja uma obra literária, uma película cinematográfica, uma peça de mobiliário, uma crença religiosa, seja a interpretação de norma de Direito Positivo, os valores aparecem como centros significativos que expressam uma preferibilidade (abstrata e geral) por certos conteúdos de expectativa, ou melhor, por certos conjuntos de conteúdos abstratamente integrados num sentido consistente. Esses símbolos de preferência por ações indeterminadas permanentes, como alude Tércio Sampaio Ferraz Júnior, ${ }^{5}$ consistindo em núcleos significativos muito abstratos, requerem outro mecanismo integrador, credenciado a imprimir-Ihes um mínimo de consistência: é a função das ideologias, conjuntos de avaliação dos próprios valores. Atuam para avaliar os valores, já que estes, por sua abstração, se mostram abertos e flexíveis. As ideologias, por isso mesmo, operam como sistemas rígidos e limitados, que hierarquizam os valores, organizando-os e permitindo que os identifiquemos. 
Muito bem. Toda vez que houver acordo, ou que um número expressivo de pessoas reconhecerem que a norma " $\mathrm{N}$ " conduz um vector axiológico forte, cumprindo papel de relevo para a compreensão de segmentos importantes do sistema de proposições prescritivas, estaremos diante de um “princípio". Quer isto significar, por outros torneios, que "princípio" é uma regra portadora de núcleos significativos de grande magnitude, influenciando, visivelmente, a orientação de cadeias normativas, às quais outorga caráter de unidade relativa, servindo de fator de agregação para outras regras do sistema positivo. Advirta-se, entretanto, que ao aludirmos a "valores" estamos indicando somente aqueles depositados pelo legislador (consciente ou inconscientemente) na linguagem do direito posto. Não cremos existir uma "região de valores", existente em si, como o topos uranos de Platão ou qualquer tipo de sistema suprapositivo de valores, ao modo de algumas vertentes jusnaturalistas. Aqueles de que nos ocupamos são os postos, centros significativos abstratos, mas positivados no ordenamento.

Se tais observações forem procedentes, cabe cogitar de uma hierarquia de valores jurídicos ou, de outra maneira, de uma classificação hierárquica das normas do Direito Positivo, elegendo-se como critério a intensidade axiológica nelas presente. Todavia, plantadas essas premissas, aquilo que se não pode admitir consoante assentamos linhas atrás, é a coalescência de "normas" e "princípios" como se fossem entidades diferentes, convivendo pacificamente no sistema das proposições prescritivas do Direito. Os princípios são normas, com todas as implicações que esta proposição apodítica venha a suscitar.

A resistência de Kelsen em compor uma teoria da interpretação fundouse, certamente, nesse profundo subjetivismo que acompanha o processo dialético de compreensão dos conteúdos normativos. Os radicais desconcertos entre as teorias doutrinárias, tendo em vista preceitos jurídicos, são exemplos eloqüentes do cabimento dessa tese. Sabemos que as mensagens prescritivas dos arts. 29 a 31, da Constituição do Brasil, realizam o "princípio da autonomia dos municípios”, confirmado pela análise do sistema vigente. Nada obstante, juristas de renome, menos inclinados ao "municipalismo" conquanto não neguem a indigitada autonomia, reduzem drasticamente a relevância dessas pessoas políticas, em suas interpretações, chegando ao ponto de designá-las por "entes menores" Esforçados nessa mesma inspiração, compreendem, ao pé da letra, o que preceitua o art. 187, parágrafo único, do Código Tributário Nacional, chegando ao resultado deplorável de admitir a "ordem" que o dispositivo estabelece, com o que relegam os Municípios a uma condição de flagrante inferioridade em face dos Estado, do Distrito Federal e da União, sobre violarem de 
maneira frontal o princípio implícito da isonomia das pessoas políticas de Direito Constitucional interno.

Desloquemos o foco da análise para o reino específico das imposições tributárias e encontraremos, desde logo, a discussão a propósito da existência ou-não do "princípio da anualidade" Já expressamos nosso entendimento segundo o qual o velho primado desaparecera com o advento da Constituição de 1967. Em sentido contrário, porém, autores de prestígio não se cansam de invocá-lo, atribuindo-lhe lugar preeminente no quadro dos mais elevados princípios constitucionais tributários.

Já podemos extrair mais duas conclusões: a) o próprio saber se u’a norma, explícita ou implícita, consubstancia um "princípio", é uma decisão inteiramente subjetiva, de cunho ideológico; e b) no que concerne ao conjunto dos princípios existentes em dado sistema, a distribuição hierárquica é função da estrutura axiológica daquele que interpreta, equivale a reconhecer, é função da sua ideologia.

6. A classificação dos "princípios" em razão dos critérios de objetividade que presidem sua aplicação aos casos concretos.

É sedutora, ao menos no exame do primeiro instante, a classificação dos princípios levando-se em conta o grau de objetividade que se verifica no momento de sua efetiva aplicação. Há princípios que são postos em termos vagos e excessivamente genéricos, ao lado de outros, enunciados de modo tão preciso, que passam a ser escassas as dissenções a respeito de sua incidência numa situação concreta. Vamos aos exemplos. A Lei Fundamental, no art. 37, caput, expressa-se de maneira vaga ao impor que a administração pública obedeça ao princípio da "moralidade", tornando-se no mínimo duvidosa e discutível sua indicação numa faixa enorme de eventos reais. A "função social da propriedade" (art. $5^{\circ}$, XXIII, da Constituição) acha-se também envolvida por forte teor de indeterminação. E o mesmo se diga da "liberdade" da "segurança" da "racionalidade". do "bem comum" da "finalidade pública" etc. bem certo que toda a palavra encerra alguma vaguidade. Mas queremos insistir que existem fórmulas expressionais onde predomina densamente a indeterminação, ao lado de outras de fácil e intuitivo reconhecimento, em que a ocorrência do mundo exterior está visivelmente demarcada, sobrando pouco espaço para os desacordos de opinião. É o caso da irretroatividade tributária (art. 150, inciso III, a, da Lei Magna). Basta saber o momento em que se deu o fato jurídico tributário e confrontá-lo com aquele que marcou o início da vigência da lei instituidora ou majoradora do tributo. Temos para nós que o princípio 
que prestigia a casa como asilo inviolável do indivíduo (art. $5^{\circ}, \mathrm{XI}$, da Constituição), bem como o que protege o sigilo de correspondência, das comunicações telegráficas e das telecomunicações telefônicas, todos eles, em maior ou menor amplitude, podem acomodar-se rigorosamente no plano da aplicação factual.

Apesar da aparente simplicidade operativa, o critério que anima essa classificação procura transmitir uma objetividade que os valores não têm, nem podem ter. A natureza eminentemente subjetiva desse núcleos significativos jamais poderá ser aprisionada, como se fora um mero fato cosmológico insularmente levado à análise. Fiquemos com sua operacionalidade, mas desde que reconheçamos a impossibilidade de fixar diretrizes objetivas e, portanto, com validade intersubjetiva, para delimitar valores. O que distrai nossa atenção entre as duas classes de princípios é que o legislador injeta valores (sempre subjetivos) em situações diferentes: incertas, indecisas, indeterminadas, as primeiras; limitadas e rigidamente delineadas, as últimas. Reflitamos sobre este tópico e estaremos autorizados a utilizar a classificação. Caso contrário seremos surpreendidos, quando o legislador empregar o mesmo valor em hipóteses abertas, sem fronteiras onde o desenho recortado do suporte fáctico (Pontes de Miranda) não corresponda aos traços que a realidade material sugerir aos nossos sentidos. Eis o princípio da "igualdade" que pode ser tomado como exemplo. Ao projetar-se num dado acontecimento do mundo, essa diretriz experimenta curiosas configurações. Sabemos quanto difícil seria sustentar a discriminação entre homens e mulheres, no processo de seleção para ingresso na carreira do Ministério Público. A singela invocação do art. $5^{\circ}$, I, da Carta Constitucional vigente, seria o bastante para tolher qualquer entendimento discriminatório. Ao mesmo tempo, em matéria publicada na Folha de São Paulo, em janeiro de 1992, Flávia Piovesan discutiu a interessante tese de benefícios pleiteados por pessoas do mesmo sexo vivendo "maritalmente" Tudo sobre o fundamento daquela norma que sobranceira, estaria impregnando o sentido das demais regras do ordenamento. Num caso, o primciro, a mera alusão ao primado da igualdade tcm a força suficiente para decidir o problema. No segundo, em que a complexidade do desenho típico se vê agravada pela presença de outros valores, numa combinatória que suscita considerações mais profundas, o mesmo princípio perde seu aparente conteúdo de objetividade não se prestando mais para, sem outros torneios retóricos, encaminhar a solução exegética.

Recobremos a lembrança de que as expressões lingüísticas conservam sempre um mínimo de vaguidade em sua integridade compositiva, inafastável por maior que seja o esforço de argumentação para efeito de convencimento. Não há como escapar 
dessa porção movediça que se aloja nos termos e nos enunciados proposicionais, alimentando, incessantemente, os estudos semânticos. Admitir esse traço, porém, longe de trazer a insegurança que desde logo imaginamos, significa reconhecer que há uma matéria-prima própria para o discursos persuasivo, tecendo a linguagem jurídica que antecede a decisão normativa.

\section{Alguns "princípios" constitucionais tributários no Sistema Positivo brasileiro.}

À moda daquelas pésquisas de laboratório, em que o cientista suspende o interesse pelas coisas do mundo para poder concentrar sua atenção cxclusivamentc no objeto que está sobre a lâmina do microscópio, vamos esquecer, por um pequeno intervalo de tempo, o sistema do Direito Positivo na sua finitude indeterminada de normas jurídicas, dirigindo nossa atenção para preceitos constitucionais que versam a temática dos tributos e, mais que isso, ostentem a estatura de renomados "princípios". De plano, uma distinção útil, porque esclarecedora: há princípios que valem para todo o ordenamento e, por via de consequiência, aplicam-se ao campo tributário; assim como há "princípios" que regem, com foros de especificidade, o desempenho da função impositiva que o Estado exerce mediante o instrumento que chamamos "tributo" Entre os dois subdomínios, fiquemos com o último, a fïm de imprimir ao presente trabalho a índole que almejamos. Sendo numerosos os comandos que o constituinte inseriu no Texto Supremo, com status de princípios tributários, separemos alguns para efeito de cxperiência. Vejamos, por exemplo, o "princípio da estrita legalidade" cravado na redação do art. 150, I, da Lei Maior. Tal diretriz aponta para a necessidade impostergável de que a entidade seja criada ou majorada por lei. Põe-se, desde já, um problema: lei no sentido estrito, isto é, lei ordinária, ou lei na sua acepção larga, vale dizer, todos os diplomas credenciados a introduzir normas inaugurais no ordenamento? Como outro elemento complicador não se pode esquecer que o sistema conecta este princípio com um valor extremamente caro para o setor: a tipicidade, isto é, ao conceber o legislador o cnte tributário, estará jungido a fixar, em sua plenitude, o desenho integral da figura lípica do gravame. Vê-se aqui uma conjunção de valores impregnando as proporções semânticas do princípio da estrita legalidade.

Sobre o da anterioridade, já assinalamos que grassa forte divergência entre os autores, no sentido de aceitá-lo como mera antecedência cronológica da lei que institui ou majora o tributo, tomando-se por referência o primeiro dia do exercício linanceiro seguinte (art. 150, III, $b$, da CF), ou como tal, acrescido do consentimento 
dos administrados, manifestado na lei orçamentária, segundo prescrevia o velho princípio da anualidade. Atinando-se à possibilidade de acatamento do princípio da anterioridade até as vésperas da exigência fiscal, fala-se hoje no princípio da nãosurpresa que predica o conhecimento antecipado, por parte do sujeito passivo, daquilo que lhe será cobrado no ano subsequiente, mas com antecedência significativa que, por falta de parâmetros constitucionais, alguns postulam ser de um ano.

Queremos insistir na tese de que onde há princípios existem valores de magnitude para o sistema e tais valores vêm sempre acompanhados de elevado grau de indeterminação. Vejamos, por exemplo, o chamado princípio da proibição de confisco. É sobremaneira difícil opinar sobre o tema, e, quando o fazemos, utilizamos mecanismos intuitivos. A propósito deste assunto lidamos com índices que, além de tudo, eles mesmos - os índices -, não podem ser objetivamente aceitos. Por certo que todos concordariam que um alíquota de $25 \%$, incidente sobre base de cálculo que tome o valor do imóvel como referência, caracterizará hipótese de confisco.

Todavia, se colhermos outro imposto, que não seja cobrado periodicamente sobre o mesmo bem, como o do exemplo, mas que incida sobre produtos de consumo, ninguém se surpreenderá com uma alíquota de $350 \%$ percutindo no valor da operação de venda. Já dissemos algures, que a doutrina do confisco não fora elaborada, permanecendo em solo estéril as construções que tomem esta figura em linha de consideração. Outro tanto se diga a respeito do princípio da capacidade econômica ou da capacidade contributiva do sujeito passivo da obrigação tributária. Por mais que a Ciência do Direito Tributário, principalmente a da Europa continental, tenha se esforçado para descrever o perfil desse primado, buscando limites e teorizando sobre possíveis demarcações práticas, nada de objetivo se realizou, permanecendo o quadro de incertezas que é, era e sempre foi. Sabe-se, quando muito, que o fato jurídico do tributo há de ser presuntivo de riqueza econômica, mesmo porque os números da pretensão impositiva hão de sair de avaliação que ele próprio ofereça. Porém, daí a pretender critérios intersubjetivamente válidos, constantes e satisfatórios, para dosar a carga tributária, vai uma distância realmente grande. Em parcelas homogêneas do universo de contribuintes ou de bens e situações que sejam tomadas como referência básica para a tributação, de fato o princípio se apresenta não-só útil e imprescindível, como de fácil manipulação. Basta, contudo, o ingresso de outro valor significativo, implicado na situação, para que as opiniões se dividam. Saquemos um exemplo atual. O IPTU (Imposto Predial e Territorial Urbano) tem como base de cálculo o valor venal do imóvel, consoante planta elaborada pelas prefeituras municipais. Ponhamos também 
entre parênteses que, por tradição, houve um acomodamento das autoridades administrativas, correspondendo ao interesse direto das pessoas tributadas, de tal modo que, neste passo, a lei nunca foi cumprida.

Inobstante isso, quantos problemas, quantas discussões se instauram, tendo como origem a cobrança dessa exação. Se a base de cálculo é o valor venal da propriedade, constante da plante de valores; se a alíquota é aquela indicada pela lei; onde estaria o ponto que irradia tantas disceptações? Afastando de cogitação o tema das atualizações, que cabe perfeitamente no espaço dos parênteses que abrimos c lechamos, não é penoso isolar casos em que a pretensão impositiva se torna discutível. Uma viúva, sem renda, que receba em herança determinado imóvel. Como atender sua obrigação tributária em relação ao IPTU? São ocorrência protocỏlares, não há dúvidas. Mas o que se quer demonstrar é que a aplicação do princípio da capacidade contributiva, para este imposto projetada sobre o "ser proprietário de bem imóvel no perímetro urbano do Município”, está plenamente satisfeita ainda que remanesça um sentimento geral de injustiça em face da pretensão do Poder Público. É que a peculiaridade do evento trouxe à toma outros valores que afetam a singela consideração da capacidade econômica do contribuinte, tornando mais complexa a compreensão do tema. $\mathrm{A}$ concretude factual permite que surjam alternativas hermenêuticas, servindo ao jogo de interesses que penetra as interações sociais e proporciona elementos para as digressões retóricas imprescindíveis ao convencimento a propósito da direção jurídica a ser tomada.

Como dissemos, há muitos princípios constitucionais tributários no Direito Positivo brasileiro, circunstância que vem justificando até o surgimento de um campo próprio de especialização nos domínios da Dogmática. Entre outros, há o trabalho clássico e pioneiro de Geraldo Ataliba (Sistema Constitucional Tributário Brasileiro) e, mais recentemente, a obra do professor Roque Carrazza, intitulada Curso de Direito Constitucional Tributário. Os dois livros, do mais elevado padrão científico, ocupamsc, exclusivamente dessa temática e tratam com especificidade, cada um dos magnos princípios que regem a atividade jurídico-tributária no Brasil.

8. "Princípios" e "sobreprincípios" - "princípios" que operam para a realização de outros "princípios" superiores na escala hierárquica.

Coloquemos entre parênteses as corriqueiras dissenções ideológicas que scparam os juristas em múltiplas direções e meditemos na organização de um conjunto qualquer de valores jurídicos. Há "princípios" e "sobreprincípios" isto é normas jurídicas que portam valores importantes e outras que aparecem pela conjunção das primeiras. Vejamos logo um exemplo: a isonomia das pessoas políticas de Direito 
Constitucional interno tem importante repercussão no setor das imposições tributárias. Não há, contudo, formulação expressa que lhe corresponda no tex to do Direito Positivo. Emerge pelo reconhecimento de outras normas que, tendo a dignidade de princípios, pelo quantum de valor que carregam consigo, fazem dele um "sobreprincípio". Rcalizasc pela atuação de outros princípios. Assim também ocorre com o primado da Justiça. Agora, há um princípio que sempre estará presente, ali onde houver direito: trata-se do cânone da certeza jurídica, entendido o termo não como garantia de previsibilidade da regulação da conduta (que é uma de suas acepções), mas como algo que se situa nos lundamentos do dever-ser, ínsita que é ao domínio do deôntico. Na sentença de um magistrado, que põe fïm a uma controvérsia, seria absurdo figurarmos um juízo de probabilidade, em que o ato jurisdicional declarasse, como exemplifica Lourival Vilanova, que "A" possivelmente deve reparar o dano causado por ato ilícito seu. Não é sentenciar, diz o mestre, ou estatuir, com pretensão de validade, o certum no conflito de condutas. $\mathrm{E}$, ainda que consideremos as obrigações alternativas, $\mathrm{cm}$ que o devedor pode optar pela prestação "A", "B" ou "C", sobre uma dela há de recair, enfaticamente, sua escolha, como imperativo inafastável da certeza jurídica. Eis outro sobre princípio, mas de feição independente, pois querendo ou-não querendo o legislador, havendo ou-não havendo justiça, segurança ou qualquer valor jurídico que se colha para a experiência, as normas do sistema hão de consagrá-lo, para poder aspirar ao sentido deôntico. Regra do direito que não discipline comportamentos intersubjetivos com observância do princípio da certeza expressará um sem-sentido na linguagem do dever-ser. Torna-se evidente que a certcza jurídica é também um sobreprincípio, mas dotado de aspectos lógicos peculiares, que the atribucm preeminência sintática com relação a todos os demais.

O campo de irradiação semântica da locução "certeza jurídica", todavia, abriga também o sentido, como dissemos, de possibilidade de previsão, pelos destinatários da mensagem normativa, do modo como se dará a regulação da conduta. Dito de outra forma, a confiança de que, acontecidos certos eventos que a norma tipifica, os dircitos e deveres prescritos estavam adredemente conhecidos, uma vez que as regras jurídicas repartem os comportamentos entre as três regiões materiais (permitido, proibido, obrigatório) e, ao fazê-lo, canaliza as condutas na direção de determinados valores. Essa proporção de sentido, mesnıo que cabível como fonte de indagação, como autêntico valor do ordenamento, tem sepre a relatividade própria das questões ideológicas. Com efeito, que se pode prever se o fato " $X$ " vai ou não ensejar a prestação jurídica "P" é alguma coisa perfeitamente admissível onde houver lim pingo de racionalidade no sistema considerado. Entretanto, saber antecipadamente, como vão 
comportar-se os sujeitos da relação, no que tange ao cumprimento do dever jurídico ou com que intensidade o titular do direito subjetivo público vai exigir ou-não o conteúdo da prestação, é assunto bem diferente. Dependerá da maneira pela qual a comunidade jurídica estiver utilizando seus signos, variação que depende de uma série de fatores cxtralingüísticos e circunstanciais, que ninguém pode prever com rigor. Estamos, aliás, na dimensão pragmática da linguagem do Direito, caracterizada por forte oscilação de tcndências c intensa variação de expectativas, responsável direta por mutações semânticas e sintáticas no conjunto dos signos.

9. Sobreprincípio da segurança jurídica no campo dos tributos.

A segurança jurídica é, por excelência, um sobreprincípio. Não temos nolícia de que algum ordenamento a contenha como regra explícita. Efetiva-se pela aluação de princípios, tais como o da legalidade, da anterioridade, da igualdade, da irretroatividade, da universalidade da jurisdição c outros mais. Isso, contudo, em termos de concepção estática, de análise das normas enquanto tais, de avaliação de um sistema normativo sem considerarmos suas projeção sobre o meio social. Se nos detivermos num Direito Positivo, historicamente dado, c isolarmos o conjunto de suas normas (tanto as somente válidas, como também as vigentes), indagando dos teores de sua racionalidade; do nível de congruência e harmonia que as proposições apresentam; dos vínculos de coordenação e de subordinação que armam os vários patamares da ordem posta; da rede de relações sintáticas c semânticas que respondem pela tessitura do todo; então será possível imitirmos um juízo de realidade que conclua pela existência do primado da segurança, justamente porque neste ordenamento empírico estão cravados aqueles valores que operam para realizá-lo. Se a esse tipo de verificação circunscrevermos nosso interesse pelo sistema, mesmo que não identifiquemos a primazia daquela diretriz, não scrá dilícil implantá-la. Bastaria instituir os valores que lhe servem de suporte, os princípios que, conjugados formariam os fundamentos a partir dos quais se levanta. Vista por csse ângulo, difícil será encontramos uına ordem jurídico-normativa que não ostente o princípio da segurança. E se o setor especulativo é o do Direito Tributário, praticamente todos os países do mundo ocidental, ao reconhecerem aqueles vetores que sc articulam axiologicamente, proclamam, na sua implicilude, essa diretriz suprema.

Nada obstante tudo que se disse, o Dircito existe para cumprir o fïm específico de regrar os comportamentos humanos, nas suas relações de interpessoalidade, implantando os valores que a sociedade almeja alcançar. As normas 
gerais e abstratas, principalmente as contidas na Lei Fundamental, exercem um papel relevantíssimo, pois são o fundamento de validade de todas as demais, indicando os rumos e os caminhos que as regras inferiores haverão de seguir, mas é naquelas individuais e concretas que o Direito se efetiva, se concretiza, se mostra como realidade normada, produto final do intenso e penoso trabalho de positivação. É o preciso instante em que a linguagem do Direito toca o tecido social, ferindo a possibilidade da conduta intersubjetiva. Daí porque não basta o trabalho preliminar de conhecer a feição estática do ordenamento positivo. Torna-se imperioso pesquisarmos o lado pragmático da linguagem normativa, para saber se os utentes desses signos os estão empregando com os efeitos que a visão estática sugere. De nada adiantam direitos e garantias individuais, placidamente inscritos na Lei Maior, se os órgãos a quem compete efetiválos não o fizerem com a dimensão que o bom uso jurídico requer. São múltiplos os exemplos que a realidade dos nossos dias oferece.

A Constituição brasileira, de 1967, previu, insistentemente (três vezes), a necessidade de lei para que qualquer obrigação tributária fosse criada. Todavia, distorcendo o conteúdo de significação que as palavras têm, as autoridades administrativas violentaram, em muitas oportunidades, aquele magno princípio. A instituição do "decreto-lei" nessa matéria, foi instrumento de iterativas transgressões a preceitos superiores. Tanto o Poder Executivo, quanto o Legislativo, utilizando o quadro de variação de sentido dos vocábulos jurídico-tributários, têm obtido orientações diversas daquelas fixadas no ordenamento, inúmeras vezes com a complacência do Poder Judiciário. Também nossa experiência com as "Medidas Provisórias" rendeu cnsejo às mais desastrosas conseqüências. Não propriamente que os defeitos estivessem contidos na estrutura mesma desses diplomas, os quais, no Brasil, têm força de lei. Mas, em virtude da manipulação extravagante e arbitrária que fez delas, medidas provisórias, instrumentos que atentavam, a cada passo, contra a integridade de valores sobranceiros da ordem juridica nacional.

A utilização inadequada de símbolos jurídico-normativos não se dá apenas com regras de "decretos-leis" ou de "medidas provisórias" diplomas que por suas próprias peculiaridades são vistos com restrições pela comunidade jurídica. A Lei n. $8.383 / 91$, que foi editada no dia 31 de dezembro, pretendendo vigorar no ano subseqüente, isto é, a partir de $1^{\circ}$ de janciro de 1992, começou a circular, tornando-se pública, tão-só no dia 2 de janeiro. Ora, segundo o princípio da anterioridade, sua vigência deveria ficar protraída para o ano seguinte (1.1.93), uma vez que o sentido de "publicar" é "dar ao conhecimento público" "tornar o ato conhecido por todos", e tal 
providência veio a realizar-se somente com a circulação, no dia 2 de janeiro de 1992 . Todavia, contra todas as expectativas, o Poder Público Federal defendeu a tese de que a "impressão" aconteceu em 21 de dezembro de 1991, o que seria suficiente para determinar a ciência dos administrados. Por mais absurda que seja a argumentação, o singelo uso de "circular", com o valor semântico de "publicar" modifica o conteúdo de significação do princípio da anterioridade, exatamente no instante máximo de sua concretude, evitando que a genuína concepção daquele primado chegue intacto ao plano das condutas intersubjetivas e desse modo, ameaçando a "segurança jurídica"

Desde logo se vê que sem atinarmos para aquilo que se passa na instância pragmática, pouco poderemos falar acerca dos valores que o sistema consagra para manter a atividade jurídico-tributária dentro de padrões de respeito para com o direito dos administrados garantindo-lhe conquistas seculares. Cremos, por isso, que as investigações relativas ao princípio da segurança jurídica, em matéria tributária, não podem prescindir de incursão por esse plano semiótico, sob pena de não compreendermos a linguagem do Direito Positivo na sua integridade constitutiva.

10. Violação de princípios e de sobreprincípios.

Quando o comando emergente de um princípio é transgredido, nem por isso estaremos autorizados a declarar que a diretriz não tem eficácia, que é "letra morta" Os sistemas de Direito Positivo prevêem a conduta infringente de suas prescrições, montando dinamismos de controle que se voltam à recomposição dos interesses violados. E sempre que esses dispositivos funcionam, restabelecendo a situação anterior, confirma-se a efetividade daqueles valores. Diante desse quadro, a desconsideração de princípios, como o da igualdade, anterioridade, legalidade estrita, entre outros, é o meio juridicamente próprio para testarmos sua eficácia. Se, quantas vezes atacados, tantas vezes reafirmado na sua força axiológica, confortavelmente poderemos afirmálo como vetor relevantíssimo do sistema.

Agora, se a agressão prospera, surte efeitos que se consolidam na ordem jurídica; se o Poder Judiciário a absorve, então se opera uma modificação no sistema, simplesmente porque a norma que hospedava certo sentido, adquire outra interpretação, passando a abrigar novos valores. E como esses valores são muito significativos, já que influenciam importantes porções de outras regras do conjunto, o antigo princípio já não se apresenta com eficácia, substituído que foi por vetores que atuam em outra direção semântica. 
Fixemo-nos, porém, num ponto: a substituição de um princípio por outro, construído por alterações que se realizam no plano pragmático, é algo natural e perfeitamente compreensível, mesmo porque a sociedade humana vive em constante mutação e os conteúdos axiológicos exercem um papel histórico, portanto delimitado no tempo. A distorção significativa a que aludimos, contudo, manifesta-se de maneira um pouco diversa: em determinado preceito do sistema se reconhece a presença de um valor, que todos apontam. Mas, no percurso da sua implantação para disciplinar as condutas em interferência intersubjetiva, ocorrem desvios, de tal sorte que ao chegar no scu destino a norma não traz a mesma orientação valorativa. Acaso se consolide a situação linal, diremos que o princípio loi violado. Entretanto, se funcionarem os dispositivos de recomposição, o princípio será rcalïrmado, saindo fortalecido.

Transportando-se a reflexão para o domínio dos sobreprincípios, em particular o da "segurança jurídica", é possível dizermos que não existirá, efetivamente, aquele valor, sempre que os princípios que o realizem forem violados. Tratando-se de entidades axiológicas, onde, como vimos, o teor de subjetividade é decisivo para identificar resultados, não cabe atinarmos a dados quantitativos, motivo pelo qual não se cogita de saber se uma única transgressão consolidada é suficiente ou se o juízo de reconhecimento requer uma sucessão delas.

\section{Conclusões.}

$1^{\text {a) }}$ Em termos de direito positivo, princípios são normas jurídicas portadoras de intensa carga axiológica, de tal forma que a compreensão de outras unidades do sistema fica na dependência da boa aplicação daqueles vetores. Acatandose o enunciado assim formulado, preserva-se a uniformidade do objeto, permanecendo o sistema do direito posto como um conjunto de normas jurídicas: todas com a mesma cstrutura sintática (homogeneidade sintática), porém diversas semanticamente (heterogeneidade semântica).

$2^{a}$ ) Assim como existe uma hierarquia sintática, podemos falar numa distribuição hierárquica dos valores jurídicos, dispostos também de maneira escalonada. Os princípios estariam ocupando posições privilegiadas nos patamares do ordenamento. E, mesmo que haja, em muitas circunstâncias, coincidência entre supremacia sintática e superioridade axiológica, a relação de correspondência não é necessária.

$3^{a}$ ) Ao mencionarmos a locução "valores jurídicos" queremos aludir àqucles plasmados na linguagem do Direito Positivo e não a outros. Temos presente 
que as discrepâncias axiológicas conduzem a interpretações diferentes da mesma unidade normativa. Tais dissonâncias, porém, se instalam em face de valores que o exegeta contrói a partir do texto, porquanto rejeitamos a tese da existência de um reino de valores suprapositivos, pairando sobre o sistema vigente. Esses núcleos significativos que revelam a preferência do legislador são depositados, consciente ou inconscientemente, na linguagem prescritiva do Direito, presidindo a seleção de aspectos lactuais e orientando a regulação das condutas intersubjetivas.

$4^{\text {a }) ~ C o m o ~ d e c o r r e ̂ n c i a ~ d e ~ t u d o ~ q u a n t o ~ f o i ~ d i t o, ~ o ~ s a b e r ~ s e ~ u ' a ~ n o r m a ~}$ consubstancia ou-não determinado princípio é uma decisão eminentemente subjetiva, de cunho ideológico.

$5^{a}$ ) Entendemos que descabe um segundo juízo de valor que, incidente sobre o primeiro, opine a respeito das proposições teoréticas do conhecimento científico, manifestando-se o jurista dogmático a respeito da Justiça, da racionalidade, da segurança ou da operacionalidade que certa ordem juŕídica apresenta ou não-apresenta. A aplicação, pela segunda vez, de uma inclinação ideológica, desvirtuaria os objetivos da Ciência, deslocando a atenção do objeto.

$\left.6^{a}\right)$ refütamos, igualmente, qualquer tentativa de aprisionar tais núcleos de significação, que chamamos de valores, por meio de esquemas objetivos, adredemente preparados. Peleja contra eles o subjetivismo ínsito ao domínio do axiológico, que não admite esquemas dessa ordem. Tudo se dá, repetimos, pela combinação dos valores do sistema. Não é de estranhar-se, por conseguinte, que ninguém tenha inventado uma fórmula adequada para indicar a presença e orientar a aplicação de princípios como o da capacidade contributiva, o da proibição de confisco, o da estrita legalidade, o da antcrioridade, o da igualdade tributária, para nos cingirmos tão-só a alguns exemplos.

$7^{\text {a) }}$ A interpretação dos princípios, como normas que verdadeiramente são, depende de uma análise sistemática que leve em consideração o universo das regras jurídicas, enquanto organização sintática (hierarquia sintática) e enquanto organização axiológica (hierarquia dos valores jurídicos), pois assim como uma proposição prescritiva do Direito não pode ser apreciada independentemente do sistema a que pertence, outro tanto acontece com os valores jurídicos injetados nas estruturas normativas. Desse processo de integração resultará o entendimento da mensagem prescritiva, em sua integridade semântica, sempre elástica e mutável.

$8^{a}$ ) Não vemos qualquer incompatibilidade entre o reconhecimento de princípios, expressos ou implícitos, e a proposta metodológica do neopositivismo lógico, seja no esquema de Hart, como na concepção de Kelsen. 
$\left.9^{a}\right)$ No Sistema Constitucional brasileiro há muitos prìncípios que versam malćria tributária, razão pela qual a compreensão desse ramo do Direito pressupõe demorada análise de preceitos da Lei Maior. Ressaltemos, dentre outros, o da igualdade, da legalidade estrita, da anterioridade, da isonomia das pessoas políticas de Direito Constitucional interno, da irretroatividade, da universalidade da jurisdição, da proibição de confisco etc.

$\left.10^{a}\right)$ Todo princípio atua para implantar seus valores. Há, contudo, conjuntos de princípios que operam para realizar, além dos respectivos conteúdos axiológicos, princípios de maior hierarquia, aos quais chamaremos de "sobreprincípios" Entre esses está o da "segurança jurídica"

$11^{a}$ ) Se num determinado sistema jurídico tributário houver a coalescência de diretrizes como a da legalidade, da igualdade, da irretroatividade, da universalidade da jurisdição, da anterioridade etc., dele diremos que abriga o sobreprincípio da segurança jurídica em matéria tributária.

$\left.12^{\mathrm{a}}\right)$ A ilação anterior, entretanto, comporta duas verificações: uma, que se dá no plano sintático-semântico; outra, no plano pragmático da linguagem jurídiconormativa.

13ª) A certificação sintático-semântica da existência daqueles princípios, em dado ordenamento, não garante o reconhecimento do sobreprimado da segurança jurídica, pois uma linguagem não pode prescindir de sua dimensão pragmática, e o Direito Positivo, como tal, é concebido para projetar-se sobre a região material das condutas intersubjetivas, disciplinando-as para a obtenção de certos valores.

$14^{a}$ ) Sendo assim, de nada adiantam direitos e garantias individuais, placidamente inscritos na Lei Magna, se os órgãos a quem compete efetivá-los não o fizerem das maneiras que o bom uso jurídico requer.

$\left.15^{a}\right)$ A circunstância de que um princípio seja transgredido, uma ou mais vezes, pouco diz sobre sua efịcácia. Impende saber se os mecanismos de recomposição, previstos pelo sistema, funcionam a ponto de restabelecer os valores ofendidos. Em caso afirmativo, teremos a manifestação de sua efetividade.

$16^{a}$ ) Não haverá respeito ao sobreprincípio da segurança jurídica sempre que as diretrizes que o realizem venham a ser concretamente desrespeitadas e tais situações infringentes se perpetuem no tempo, consolidando-se.

São Paulo, julho de 2003. 